\title{
Immunoglobulin allotypes in Crohn's disease in the Netherlands
}

\author{
I BIEMOND, GERDA G DE LANGE, IRENE T WETERMAN,
} AND A S PEÑA

From the Department of Gastroenterology and Hepatology, University Hospital, Leiden, and the Central Laboratory of the Netherlands Red Cross Blood Transfusion Service, Amsterdam, The Netherlands

SUMmaRY An association between Crohn's disease and immunoglobulin allotypes has been reported. Confirmation of this association in other populations would be of particular importance for the study of hereditary factors in Crohn's disease. In the present study we have typed 155 unrelated Dutch patients with Crohn's disease and 450 blood donors for the Gm, Am, and Km markers. No significant differences were found in $\mathrm{Gm}$ phenotypes and haplotypes between patients and controls. It therefore seems unlikely that the immunoglobulin allotypes play an important role in the susceptibility of individuals to Crohn's disease.

The aetiology of Crohn's disease is unknown, but individual susceptibility seems to be influenced by genetic and environmental factors.

The high familial incidence, especially in first degree relatives, the rarity of nuclear families with both parents affected, and the high concordance of the disease in monozygotic twins as compared with dizygotic twins, strongly suggest an important role of genetic factors in the causation of the disease. ' Until now, however, such a factor has not been established unequivocally and consistently. An association between Crohn's disease and immunoglobulin allotypes was described recently by Kagnoff et al, ${ }^{2}$ who found that for caucasoids with the $\mathrm{Gm}$ phenotype $(\mathrm{a}, \mathrm{x}, \mathrm{f} ; \mathrm{b}, \mathrm{g})$ the relative risk of developing Crohn's disease was $3 \cdot 17$. The influence of the immunoglobulin allotypes on the incidence of Crohn's disease in a particular population can be estimated with the population attributable risk which is often referred as the aetiologic fraction, ${ }^{3}$ which takes into account the relative risk and the relative frequency of the factor under study. Further analysis of the data reported by Kagnoff $e t$ al $^{2}$ gave a population attributable risk of $26 \%$, which means that $26 \%$ of the incidence of Crohn's disease can be attributed to the existence of individuals with the described $\mathrm{Gm}$ phenotype $(a, x, f ; b, g)$ in the general population under study.

Address for correspondence: Ir I Biemond. Department of Gastroenterology and Hepatology. University Hospital. Building 1, C4-P. Rijnsburgerweg 10, 23.3. AA Leiden, The Netherlands.

Received for publication 3 October 1986.
The presence of this phenotype could therefore contribute considerably to the susceptibility for Crohn's disease. Confirmation of this association in other populations would be of particular importance for the study of hereditary factors in Crohn's disease. This led us to type 155 Dutch patients with Crohn's disease for the G1m, G2m, G3m, A2m, and $\mathrm{Km}$ allotypes, which are polymorphic determinants of immunoglobulins located on the heavy chains of IgG1, IgG2, IgG3, and IgA2, and on the kappa light chains, respectively. The phenotype and haplotype frequencies were compared with those of healthy individuals.

\section{Methods}

PATIENTS

One hundred and fifty five unrelated patients suffering from Crohn's disease were bled between July 1981 and July 1982. Most of them were outpatients; the others were investigated during an admission to the ward of the department of gastroenterology. The diagnosis of Crohn's disease was established on the basis of clinical, radiological, and histological criteria. ${ }^{+}$

The mean age at the time of the study was 39 years (range 16-79 years). There were 69 men and 86 women. The site of the disease at time of first referral to the Leiden University Hospital was in the distal part of the small intestine in $38.1 \%$ of patients, in both the ileum and the colon in $30.3 \%$, and in the colon alone in $29.7 \%$; the other patients had the 
disease at that time in the distal part of the rectum and perianal lesions or only the latter, but during the follow up the disease developed in a way that fitted to Crohn's disease.

\section{CONTROLS}

Phenotype and haplotype frequencies were compared with those of 450 Dutch blood donors.

TYPING

Typing was carried out in the Central Laboratory of the Netherlands Red Cross Transfusion Service in Amsterdam for the following markers: $\operatorname{Glm}(\mathrm{z}, \mathrm{a}, \mathrm{x}, \mathrm{f})$, $\mathrm{G} 2 \mathrm{~m}(\mathrm{n}), \mathrm{G} 3 \mathrm{~m}(\mathrm{~g}, \mathrm{~b} 0, \mathrm{~b} 1, \mathrm{~b} 3, \mathrm{~b} 5, \mathrm{~s}, \mathrm{t}, \mathrm{c} 3, \mathrm{c} 5), \mathrm{A} 2 \mathrm{~m}(1,2)$, and $\operatorname{Km}(1,3)$. The notation used for allotypic markers on immunoglobulins follows the recommendations of the World Health Organisation." Typing was carried out with the conventional agglutination inhibition technique." The reagents used are described elsewhere. ${ }^{7}$ All samples were tested in two dilutions, 1:20 and 1:60, in microtitre plates. When disturbing antibodies were present, the samples were heated for $10 \mathrm{~min}$ at $65^{\circ} \mathrm{C}$ and retested in three dilutions.?

\section{STATISTICAL ANALYSIS}

The $\chi^{2}$ for $2 \times k$ and $2 \times 2$ contingency tables was calculated according to the principles of Pearson. ${ }^{*}$ The $\chi^{2}$ value for the $2 \times 2$ tables was corrected for continuity according to Yates."

Haplotype frequencies were estimated with the maximum likelihood method, using the computer program MAXLIK."'

Comparison of haplotype frequencies between patients and controls was done by estimating the standardised normal deviate $(Z)$ from the quotient of the difference in haplotype frequencies of cases and controls and the standard error of the pooled haplotype frequency" corrected for continuity. ${ }^{\prime}$

Table 1 Gm phenotypes in patients with Crohn's disease and blood donors

\begin{tabular}{|c|c|c|c|c|}
\hline \multirow{2}{*}{$\begin{array}{l}\text { Gm phenotype } \\
G 1 m ; G 2 m ; G 3 m\end{array}$} & \multicolumn{2}{|c|}{$\begin{array}{l}\text { Crohn's disease patients } \\
(n=155)\end{array}$} & \multicolumn{2}{|c|}{$\begin{array}{l}\text { Controls } \\
(n=450)\end{array}$} \\
\hline & $n$ & $\%$ & $n$ & $\%$ \\
\hline $\mathbf{f} ; \mathbf{n} ; \mathbf{b}$ & 62 & 4()$\cdot()$ & 207 & $46 \cdot 0$ \\
\hline zaf; n;gb & 23 & $14 \cdot 8$ & 71 & $15 \cdot 8$ \\
\hline zaxf; n;gb & 18 & $11 \cdot 6$ & 34 & $7 \cdot 6$ \\
\hline zaf; .. ;gb & 13 & $8 \cdot 4$ & 35 & $7 \cdot 8$ \\
\hline f; $\ldots ; b$ & 11 & $7 \cdot 1$ & 29 & $6 \cdot 4$ \\
\hline$z a x ; \ldots ; g$ & 7 & $4 \cdot 5$ & 16 & 3.6 \\
\hline zaxf;... ;gb & 6 & 3.9 & 26 & $5 \cdot 8$ \\
\hline$z a ; \ldots ; g$ & 4 & $2 \cdot 6$ & 18 & $4 \cdot()$ \\
\hline Others & 11 & $7 \cdot 1$ & 14 & $3 \cdot 1$ \\
\hline
\end{tabular}

\section{Results}

The absolute and relative frequencies of Gm phenotypes are shown in Table 1. The distribution of phenotypes did not differ between patients and controls $\left(\chi^{2}=9.48 ; \mathrm{df}=8 ; 0.25<\mathrm{p}<0.5\right)$. The frequencies of haplotypes in patients with Crohn's disease are almost the same as those found in the Dutch controls, as can be seen in Table 2 .

No difference $\left(\chi^{2}=0.53 ; p>0.05\right)$ was detected between the frequency of the $\mathrm{Km}(1)$ allotypic marker in patients $(16 \cdot 1 \%)$ and controls $(13 \cdot 3 \%)$. For the patients, a relative frequency of $3 \cdot 2 \%$ was found for the $\mathrm{A} 2 \mathrm{~m}(2)$ allotypic marker and the frequency of this marker in the Dutch population was found to be $4.9 \%$, which is not significantly different $\left(\chi^{2}=0.41\right.$; $\mathrm{p}>0.05)$.

\section{Discussion}

To our knowledge only four case control studies have been done to investigate the distribution of immunoglobulin allotypes in Crohn's disease. Three studies including our own have been done independently in Dutch patients suffering from Crohn's disease. Regrettably, the data of the previous study, done in Amsterdam, ${ }^{12}$ have not been published in detail, but the report stated that no deviation from control frequencies was observed and in a study done in Groningen ${ }^{13}$ the same conclusion was reached. These three independent studies done in The Netherlands failed to detect any $\mathrm{Gm}$ phenotype or haplotype associated with Crohn's disease. This is in contrast with the findings of Kagnoff et al in 68 North American caucasoids of North European ancestry suffering from Crohn's disease, which showed a strong association with $\mathrm{Gm}$ phenotype $(\mathrm{a}, \mathrm{x}, \mathrm{f} ; \mathrm{g}, \mathrm{b})$ and haplotype $\mathrm{Gm}^{\mathrm{a}} \mathrm{x}: \mathrm{g}$. The antigens $\mathrm{G} 1 \mathrm{~m}(\mathrm{z})$ and

Table 2 Frequency of $\mathrm{Gm}$ haplotypes in patients with Crohn's disease and blood donors

\begin{tabular}{|c|c|c|c|c|}
\hline \multirow{2}{*}{$\begin{array}{l}\text { Gm haplotype } \\
G 1 m ; G 2 m ; G 3 m\end{array}$} & \multicolumn{2}{|c|}{$\begin{array}{l}\text { Crohn's disease patients } \\
(n=155)\end{array}$} & \multicolumn{2}{|l|}{$\begin{array}{l}\text { Controls } \\
(n=450)\end{array}$} \\
\hline & $H F^{*}$ & $S E$ & $H F$ & $S E$ \\
\hline$f ; n ; b$ & 0.4429 & $0 \cdot() 331$ & 0.4628 & 0.0195 \\
\hline$f ; \ldots ; b$ & $0 \cdot 2465$ & $(0.0299$ & $(0.2574$ & $(0) \cdot() 177$ \\
\hline$z a ; \ldots ; g$ & $0 \cdot 1648$ & $0 .(0219$ & $(0.1747$ & $(0.0129$ \\
\hline$z a x ; . . ; g$ & 0.1096 & $0 \cdot 0185$ & $(0.0895$ & 0.0098 \\
\hline Others & $\underline{0.0361}$ & $(0 \cdot(0107$ & 0.0157 & $(0 \cdot()() 42$ \\
\hline$\Sigma \mathrm{HF}_{\mathrm{i}}$ & \multicolumn{2}{|c|}{$\overline{0.9999}$} & \multicolumn{2}{|l|}{$\overline{1 \cdot()(x) 1}$} \\
\hline$x_{4}^{2+}$ & \multicolumn{2}{|c|}{$1.655(\mathrm{NS})$} & \multicolumn{2}{|l|}{3.97 (NS) } \\
\hline
\end{tabular}


$\mathrm{G} 2 \mathrm{~m}(\mathrm{n})$ were not included in the North American study.

Comparison of the phenotype distribution between patients in North America and Leiden revealed a significant difference in the phenotypic distribution $\left(\chi^{2}=12 \cdot 24 ; \mathrm{df}=4 ; \mathrm{p}<0 \cdot 025\right)$. This difference can be attributed to the significantly higher frequency of the $\mathrm{Gm}$ phenotype $(\mathrm{a}, \mathrm{x}, \mathrm{f} ; \mathrm{b}, \mathrm{g})$ in the North American Crohn's patients (38.2 v 16.7\%; $\chi$ ' Yates corrected $=10 \cdot 76 ; p=0 \cdot(0014)$.

Distortion of the $\mathrm{Gm}$ phenotypic distribution can also be explained by selection bias. Selection bias in Kagnoff $e t$ al's's study could have been introduced by, for example, consanguinity or the inclusion of patients recently given a blood transfusion. It is unclear from this report whether all of their patients were unrelated, and the exclusion criteria of the National Cooperative Crohn's Disease Study do not include blood relationship. ${ }^{1+}$ This seems to be unlikely, however.

The presence of phenotype $\mathrm{Gm}(\mathrm{a}, \mathrm{x}, \mathrm{f} ; \mathrm{b}, \mathrm{g})$ could be caused by recent blood transfusions, but in that case we would have expected a higher frequency of the $\mathrm{Gm}(\mathrm{n})$ and the $\mathrm{Km}(1)$ markers in the patients too, and this was not found.

In summary, at present we do not have an adequate explanation for the different results obtained in the USA and in The Netherlands. We have concluded that as immunoglobulin allotypes have not been found consistently associated with Crohn's disease in different populations, this genetic polymorphism seems to be of little value for an understanding of the genetic predisposition of Crohn's disease.

The authors wish to thank Dr W S Volkers of the Department of Human Genetics of Leiden University for providing the computer program MAXLIK, Mr $\mathrm{P} H$ van Eede and $\mathrm{Mr}$ A M van Leeuwen for excellent technical assistance, and Miss Karlien Kruijer for typing the manuscript.

\section{References}

1 Weterman IT, Peña AS. Familial incidence of Crohn's disease in The Netherlands and a review of the literature. Gastroenterology 1984; 86: 449-52.

2 Kagnoff MF, Brown RJ, Schanfield MS. Association between Crohn's disease and immunoglobulin heavy chain (Gm) allotypes. Gastroenterology 1983; 5: 1044-7.

3 Miettinen OS. Proportion of disease caused or prevented by a given exposure, trait or intervention. Am J Epidemiol 1974; 99: 325-32.

4 Lennard-Jones JE. Definition and diagnosis. In: Engel A, Larsson T, eds. Regional enteritis (Crohn's disease). Stockholm: Nordiska Bokhandelns Förlag, 1971: $105-15$.

5 Review of notation for the allotypic and related markers of human immunoglobulins. Eur J Immunol 1976; 6: 599-601.

6 Loghem E van. Genetic studies on human immunoglobulins. In: Weir DM, ed. Handbook of experimental immunology. Vol 1. Immunochemistry. Oxford: Blackwell, 1978: 11.1-11.16.

7 Lange $G$ de, Wright $P$, Eede $P$ van, Leeuwen F van, Thuy Long H, Diem Hong NT. Association between leprosy and immunoglobulin allotypes: $\mathrm{Gm}-\mathrm{A} 2 \mathrm{~m}$ and $\mathrm{Km}$ frequencies in Vietnamese. J Immunogenet 1984; 11: $173-80$

8 Pearson $\mathrm{K}$. On the criterion that a given system of deviations from the probable in the case of a correlated system of variables is such that it can be reasonably supposed to have arisen from random sampling. Philos Mag 1900; ser 5, 50: 157-75.

9 Yates F. Contingency tables involving small numbers and the $\chi^{2}$ test. J R Stat Soc Suppl 1934; 1: 217-35.

10 Reed TE, Schull WJ. A general maximum likelihood estimation program [Letter]. Am J Human Genet 1968; 20: $579-80$.

11 Armitage P. Statistical methods in medical research. Oxford: Blackwell, 1971.

12 Berg-Loonen van den EM, Dekker-Saeys BJ, Meuwissen SGM, Nijenhuis LE, Engelfriet CP. Histocompatibility antigens and other genetic markers in ankylosing spondylitis and inflammatory bowel diseases. J Immunogenet 1977; 4: 167-75.

13 Ockhuizen Th, Westra H, Bijzet J, Post JG, Vanleeuwen MA, Vanrijswijk MH. Immunoglobulin allotypes are not involved in systemic amyloidosis. J Rheumatol 1985; 12: $742-5$.

14 Winship DH, Summers RW, Singleton JW, et al. National Cooperative Crohn's disease study: study design and conduct of the study. Gastroenterology 1979; 77: 829-42. 